\title{
Retinopathy of prematurity in a cohort of neonates at Groote Schuur Hospital, Cape Town, South Africa
}

\author{
Q Keraan, ${ }^{1}$ MB ChB, FC Paed (SA), Cert Neonatology (SA), MPhil (Neonatol); C Tinley, ${ }^{2}$ MB ChB, FRC Ophth; \\ A Horn, ${ }^{3} \mathrm{MB}$ ChB, DCH (SA), FC Paed (SA), Cert Neonatology (SA), PhD; T Pollock, ${ }^{2}$ MB ChB, FCS Ophth (SA); \\ J Steffen, ${ }^{4}$ MB ChB, FC Ophth (SA), MMed Ophth; Y Joolay, ${ }^{3}$ MB ChB, FC Paed (SA), Cert Neonatology (SA), MPhil Neonatology \\ ${ }^{1}$ Private practice, Cape Town, South Africa (previously affiliated to Neonatal Medicine, Groote Schuur Hospital, Cape Town; and \\ Department of Paediatrics, Faculty of Health Sciences, University of Cape Town, South Africa) \\ ${ }^{2}$ Department of Ophthalmology, Red Cross War Memorial Children's Hospital, Cape Town, and Faculty of Health Sciences, University of \\ Cape Town, South Africa \\ ${ }^{3}$ Neonatal Medicine, Groote Schuur Hospital, Cape Town; and Department of Paediatrics, Faculty of Health Sciences, University of Cape Town, \\ South Africa \\ ${ }^{4}$ Department of Ophthalmology, Groote Schuur Hospital, Cape Town, and Faculty of Health Sciences, University of Cape Town, South Africa
}

Corresponding author: Y Joolay (yaseen.joolay@uct.ac.za)

\begin{abstract}
Background. Severe retinopathy of prematurity (ROP) can cause blindness. Before 2016, resource limitations precluded routine screening for ROP at Groote Schuur Hospital (GSH), Cape Town, South Africa. Previous pilot studies at GSH found no patients with ROP requiring treatment; however, improved preterm infant survival may affect the prevalence.

Objectives. To determine the prevalence and severity of ROP, describe potential risk factors, and assess the feasibility of ROP screening. Methods. Infants with a birth weight (BW) of $<1251 \mathrm{~g}$ or a gestational age (GA) of $\leq 31$ weeks were screened from November 2012 to May 2013.

Results. Three hundred and thirteen ROP examinations were performed in 135 of 191 eligible infants. The mean GA and BW were 30.1 weeks (standard deviation (SD) 1.9) and $1056 \mathrm{~g}$ (SD 172), respectively. ROP was diagnosed in 40 infants (29.6\%); 8 (5.9\%) had severe ROP and $2(1.5 \%)$ received laser treatment. Infants with ROP had a lower mean GA (29.2 weeks (SD 1.6) v. 30.5 weeks (SD 1.9)) ( $p<0.002)$ and a lower mean BW (988 g (SD 181) v. $1085 \mathrm{~g}$ (SD 160)) ( $p=0.001)$ than those without ROP. Infants weighing $<1000 \mathrm{~g}$ had a 2.5 times higher risk than those with a BW of $\geq 1000 \mathrm{~g}$ of having ROP (95\% confidence interval $1.05-5.90 ; p=0.03)$. Blood transfusions $(p<0.002)$ and late-onset sepsis $(p=0.024)$ were strongly associated with ROP. Screening was completed in $91.1 \%(123 / 135)$ of the infants.

Conclusions. The prevalence and severity of ROP have increased at GSH. The strong association between ROP, BW and GA suggests that infants with lower BWs and GAs should be prioritised for screening in our resource-limited setting.
\end{abstract}

S Afr Med J 2017;107(1):64-69. DOI:10.7196/SAMJ.2017.v107i1.11226

Retinopathy of prematurity (ROP) is a preventable cause of visual impairment in premature neonates. ${ }^{[1]}$ Screening and early treatment are important to prevent related morbidity. An increase in ROP has been reported in middle-income countries, as greater numbers of premature infants survive as a result of improved neonatal care, but lack adequately monitored oxygen therapy. ${ }^{[2]}$ The ROP Working Group of South Africa (SA) has recommended guidelines for the prevention, screening and treatment of ROP for SA, based on international guidelines. ${ }^{[3]}$ The United South African Neonatal Association, the Ophthalmological Society of South Africa and the South African Vitreoretinal Society have endorsed these recommendations, but resource limitations are acknowledged as a limiting factor in implementation of these guidelines.

The neonatal unit at Groote Schuur Hospital (GSH), Cape Town, SA, provides tertiary care for $>500$ very low-birth-weight (VLBW) and extremely low-birth-weight (ELBW) premature infants from the West Metro region of the Western Cape Province per year. A study at GSH in 1991 by Straker and Van der Elst, ${ }^{[4]}$ as well as an unpublished study in 2001 (J C Richards, 'Prospective evaluation of retinopathy of prematurity screening policy for neonatal units allied to the University of Cape Town'), did not detect any ROP requiring treatment. Based on these findings and resource constraints, an ROP screening service was not instituted.
More recent data from other tertiary SA hospitals suggested that a review is required. Studies between 1995 and 2013 reported a prevalence of ROP ranging from $16.3 \%$ to $31.1 \% .^{[5-8]}$ The prevalence of severe ROP ranged from $4.3 \%$ to $7.1 \%$, with no infant weighing $>1250 \mathrm{~g}$ requiring treatment. These studies all reported infants requiring treatment for ROP. Based on these data, we secured funding to conduct a 6-month pilot study. The objectives of the study were to: (i) determine the prevalence and severity of ROP in a prospective cohort of preterm infants; (ii) describe the association of prespecified potential risk factors; and (iii) assess the feasibility of screening for ROP in a relatively resource-limited setting.

\section{Methods}

A prospective cohort study of a pilot ROP screening programme was conducted at GSH from November 2012 to May 2013. This study was approved by the Human Research Ethics Committee, Faculty of Health Sciences, University of Cape Town (HREC/REF: 509/2012) and conformed to the principles of the 2013 Declaration of Helsinki. ${ }^{\left[{ }^{[]}\right.}$

Inclusion criteria for screening were a birth weight (BW) of $<1251 \mathrm{~g}$ or birth gestational age (GA), confirmed by a Ballard score, of $\leq 31$ weeks at birth. Patients with lethal congenital conditions or those whose parents refused consent for screening were excluded. Written informed parental consent was obtained for ROP examination and 
inclusion into the study. Consent was obtained from the medical superintendent for infants being fostered or adopted.

\section{Medical management}

The 2010 International Liaison Committee on Resuscitation guideline $^{[10]}$ was followed. Infants were monitored with pulse oximetry, targeting saturations of $88-92 \%$. Exclusive breastmilk feeds were encouraged for all infants, donor breastmilk being variably available to infants weighing $<1200 \mathrm{~g}$. Cranial ultrasound scans were performed in the first week of life and repeated at discharge, or earlier if indicated.

\section{Screening ophthalmic examination}

A paediatric ophthalmologist examined infants once a week. The neonatal unit's admissions book was reviewed daily to identify eligible infants. A register and diary were kept to facilitate the timing of examinations. The first examination occurred at 4 weeks' chronological age or at 32 weeks' corrected GA, whichever occurred later. Examination was deferred in clinically unstable infants. A research assistant was employed for the duration of the study to complete administration and assist during examinations. Combination cyclopentolate hydrochloride and phenylephrine hydrochloride drops, one drop every 15 minutes up to a maximum of three, were instilled into each eye in preparation for screening. Benoxinate hydrochloride $0.4 \%$ was used as a local anaesthetic. Inpatients were monitored as per standard practice in the neonatal unit. Outpatients were discharged once they had been successfully fed after the examination. The infants' retinas were examined by binocular indirect ophthalmoscopy. The ophthalmologist determined follow-up according to standard guidelines. ${ }^{[11]}$

If infants were transferred, receiving hospitals were informed that screening needed to be completed. On discharge, appointments were communicated to parents and documented. As a reminder, both receiving hospitals and outpatients were contacted by telephone 3 days prior to appointments. If three consecutive appointments were missed, no further contact was attempted. However, if the research assistant was contacted, a booking was made for the next session.

Infants were discharged from screening according to recommended SA guidelines. ${ }^{[3]}$ Initial and subsequent follow-up was done at the GSH neonatal unit. Infants requiring prolonged follow-up were reviewed at the ophthalmology outpatient clinic at Red Cross War Memorial Children's Hospital, Cape Town. A maximum of 20 patients were examined per session.

\section{Treatment of ROP}

Treatment was administered according to the Early Treatment for Retinopathy of Prematurity Randomized Trial guidelines. ${ }^{[12]}$ A retinal specialist performed laser treatment in the neonatal unit within 72 hours of diagnosis.

\section{Data collection and statistical analysis}

Data collected included demographic details as well as clinical information such as the occurrence of early ( $<72$ hours after delivery) or late ( $\geq 72$ hours after delivery) onset of sepsis, intraventricular/ periventricular haemorrhage (grade 3 or 4 ), and type of enteral nutrition received in the first 6 weeks of life.

Findings of screening examination were recorded, including the presence or absence of ROP, grade of ROP if present (International Classification of Retinopathy of Prematurity revisited $\left.{ }^{[13]}\right)$, findings at follow-up examination and the need for ROP treatment.

Stata version 12 (StataCorp, USA) was used for statistical analysis. Demographic and clinical data were presented with descriptive statistical methods. Comparative statistical analysis was done on infants grouped according to the presence of ROP v. infants with no ROP as a primary outcome. Further analysis was done to compare infants with no or only mild ROP with those who had clinically significant ROP (CSROP). The presence of stage 3 ROP or any stage of ROP with plus disease was classified as CSROP.

Factors associated with different grades of severity were described. The $\chi^{2}$ test or Fisher's exact test was used for categorical comparisons, depending on the expected values. Student's $t$-test and the Wilcoxon rank-sum test were used for comparison of parametric and nonparametric continuous variables, respectively. All statistical tests were two-sided at alpha $=0.05$. Multivariate analysis was performed on statistically significant risk factors $(p<0.2)$. Multivariate analysis was done using a Poisson regression model with a robust error variance for relative risk.

\section{Results}

Screening was performed in 135 of the 191 eligible infants. Fig. 1 shows the derivation of the final dataset. The prespecified perinatal characteristics of the cohort are shown in Table 1. The mean GA and BW were 30.1 weeks (standard deviation (SD) 1.9) and $1056 \mathrm{~g}$ (SD 172), respectively. Seventy-four infants (54.8\%) were female. Only black $(57.1 \%)$ and coloured $(42.9 \%)$ infants were represented in the sample. One infant had a family history of ROP.

In total, 313 examinations were performed; $38.5 \%$ of infants required one, $31.9 \%$ two and $16.3 \%$ four or more examinations. Three infants (2.2\%) had eight ROP examinations.

ROP was diagnosed in 40 infants (29.6\%); 8 (5.9\%) had CSROP. No infant had stage 4 or 5 ROP. Stage 3 ROP occurred in only one infant with a BW >1 $250 \mathrm{~g}$, but regressed and did not require treatment. Two infants received laser treatment. Screening was completed in 91.1\% (123/135). Twelve infants were lost to follow-up. Of these, 7 (58.3\%) had ROP and 2 (16.7\%) had CSROP.

Table 2 shows comparisons of prespecified potential risk factors. Infants with ROP had a lower mean GA and BW than those without ROP: 29.2 weeks (SD 1.6) v. 30.5 weeks (SD 1.9) $(p<0.002)$ and $988 \mathrm{~g}$ (SD 181) v. $1085 \mathrm{~g}$ (SD 160) ( $p=0.001)$, respectively. Infants with ROP were more likely than those without to have received a blood transfusion $(p<0.002)$ (Fig. 2), to have late-onset sepsis $(p=0.024)$ (Fig. 3), and to have received exclusive breastmilk feeds ( $p=0.005$ ).

There were no statistically significant differences in potential risk factor exposure in infants with mild ROP or CSROP. A comparison of potential risk factors between infants with CSROP and those with either mild ROP or no ROP (Table 2) showed that infants delivered via caesarean section were less likely to develop CSROP $(p=0.007)$.

On multivariate analysis, GA at birth was the only variable independently associated with ROP (risk ratio (RR) $0.85,95 \%$ confidence interval (CI) $0.740-0.988 ; p=0.03$ ). If $\mathrm{GA}$ was excluded, BW (RR 0.99, 95\% CI $0.997-0.999 ; p=0.03$ ) and blood transfusions (RR 1.71, 95\% CI $1.027-2.859$; $p=0.03$ ) were independently associated with ROP. ELBW infants had a 2.5 times higher risk of having ROP than infants with a BW $\geq 1000 \mathrm{~g}$ (95\% CI 1.05 - 5.90; $p=0.03$ ). The prevalence of ROP according to BW is described further in Fig. 4.

\section{Discussion}

ROP occurred in $29.6 \%$ of the study cohort; $5.9 \%$ developed CSROP and $2(1.5 \%)$ received laser treatment. Infants who required treatment weighed $<1250 \mathrm{~g}$ at birth. This prevalence is significantly higher than in previous studies at GSH.[4,5] Infrastructure and resources in the healthcare facilities referring to GSH have improved in the past two decades. Additionally, surfactant therapy and non-invasive ventilation are more accessible, contributing to improved preterm 


\begin{tabular}{|c|c|}
\hline \multicolumn{2}{|l|}{ Infant characteristics } \\
\hline BW $(g)$, mean $(S D)$ & $1056(172)$ \\
\hline GA (wk), mean (SD) & $30.1(1.9)$ \\
\hline \multicolumn{2}{|l|}{ Racial group, $n(\%)$} \\
\hline Black & $77(57.0)$ \\
\hline Coloured & $58(43.0)$ \\
\hline Female gender, $n(\%)$ & $74(54.8)$ \\
\hline Family history of ROP, $n(\%)$ & $1(0.7)$ \\
\hline \multicolumn{2}{|l|}{ Maternal history, $n(\%)$} \\
\hline Mother VDRL-positive & $2(1.5)$ \\
\hline Mother HIV-positive & $22(16.3)$ \\
\hline Maternal medication use & $58(43.0)$ \\
\hline Cigarettes/tik/alcohol use & $16(11.9)$ \\
\hline Illness & $73(54.9)$ \\
\hline \multicolumn{2}{|l|}{ Birth and resuscitation history } \\
\hline Outborn, $n(\%)$ & $10(7.4)$ \\
\hline Mode of delivery CS, $n$ (\%) & $95(71.1)$ \\
\hline \multicolumn{2}{|l|}{ Apgar score ( $N=133)$, median (IQR) } \\
\hline $1 \mathrm{~min}$ & $7(4-8)$ \\
\hline $5 \mathrm{~min}$ & $9(7-9)$ \\
\hline Resuscitation required $(N=131), n(\%)$ & $85(64.9)$ \\
\hline Oxygen administered & $103(76.3)$ \\
\hline Facemask/T-piece ventilation $(N=131), n(\%)$ & $85(64.9)$ \\
\hline Endotracheal intubation $(N=131), n(\%)$ & $13(9.9)$ \\
\hline Chest compressions ( $N=131), n(\%)$ & $26(19.9)$ \\
\hline \multicolumn{2}{|l|}{ Neonatal period } \\
\hline \multicolumn{2}{|l|}{ Respiratory support } \\
\hline $\mathrm{O}_{2}$ therapy, $n(\%)$ & $122(90.4)$ \\
\hline CPAP/HHFNC/nasal cannula $\mathrm{O}_{2}, n(\%)$ & $95(70.4)$ \\
\hline Mechanical ventilation, $n(\%)$ & $27(20.0)$ \\
\hline $\begin{array}{l}\text { Duration of } \mathrm{O}_{2} \text { therapy (days), median } \\
\text { (IQR) }\end{array}$ & $5(2-10)$ \\
\hline $\begin{array}{l}\text { Highest concentration of } \mathrm{O}_{2} \text { received, } \\
\text { median (IQR) }\end{array}$ & $\begin{array}{l}0.3(0.25- \\
0.37)\end{array}$ \\
\hline Surfactant, $n(\%)$ & $40(29.6)$ \\
\hline Apnoea, $n(\%)$ & $37(27.4)$ \\
\hline Blood transfusion, $n(\%)$ & $28(20.7)$ \\
\hline \multicolumn{2}{|l|}{ Sepsis, $n(\%)$} \\
\hline Early & $1(0.7)$ \\
\hline Late & $7(5.2)$ \\
\hline IVH (grade 3 or 4$)(N=132), n(\%)$ & $4(3.0)$ \\
\hline Exclusive breastmilk feeds, $n$ (\%) & $50(37.0)$ \\
\hline
\end{tabular}

survival. ${ }^{[14]}$ Straker and Van der Elst ${ }^{[4]}$ reported a prevalence of ROP of $19.2 \%$, including all infants with a BW of $<1500 \mathrm{~g} ; 1.5 \%$ of infants developed severe ROP and no infant required treatment. However, infants in their study were small for GA. The lower weight inclusion

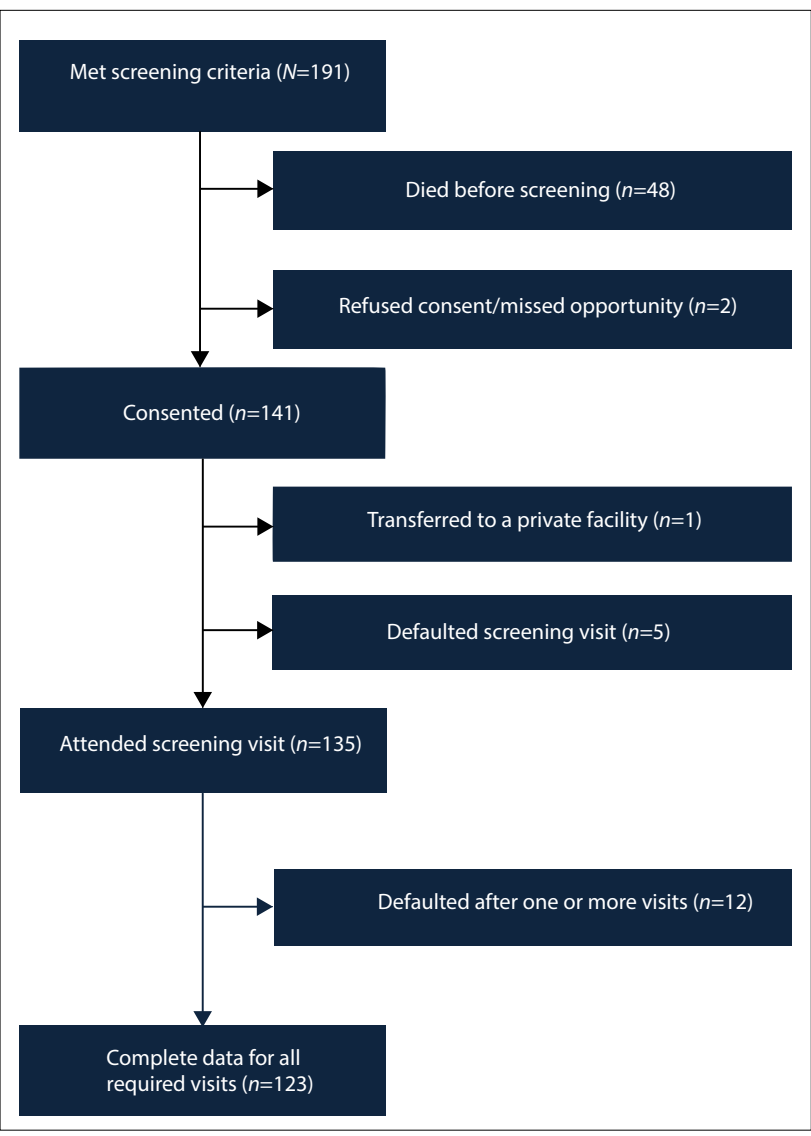

Fig. 1. Derivation of the final data set.

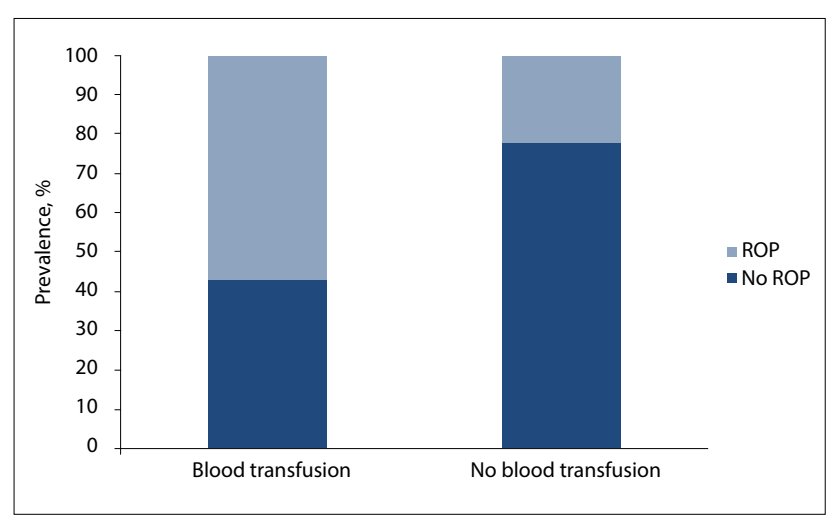

Fig. 2. Prevalence of ROP in infants receiving blood transfusions ( $\mathrm{N}=135)$.

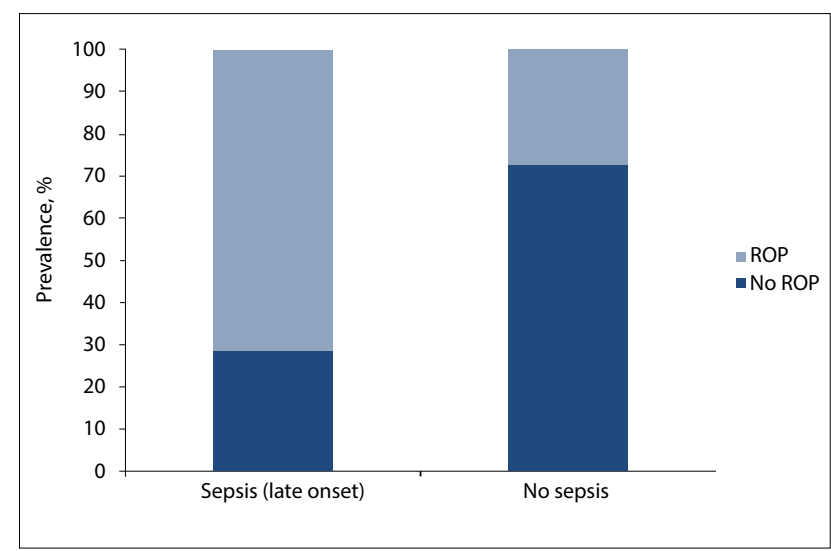

Fig. 3. Prevalence of ROP in infants with late-onset sepsis $(\mathrm{N}=135)$. 


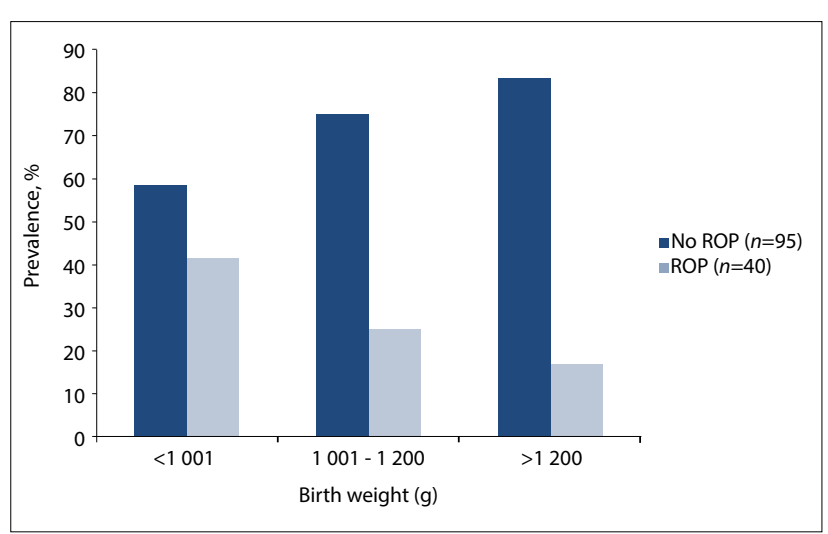

Fig. 4. Prevalence of ROP in $B W$ categories $(\mathrm{N}=135)$.

criteria in our study, with a potentially greater proportion of less mature infants being included, may explain the higher prevalence of ROP. Growth restriction was not specifically assessed. Richards (unpublished data) reported an overall ROP prevalence of 3.6\% in infants weighing $<1500 \mathrm{~g}$, increasing to $14.5 \%$ in the subgroup of $<28$ weeks' GA at birth, with no infant requiring treatment. However, infants were assessed at 6 weeks' chronological age and then again at term if no ROP was initially detected, potentially missing infants who developed ROP that then regressed before review. Repeat examinations in our study occurred more frequently, every 2 - 3 weeks. In Richards' unpublished study, $73 \%$ of infants attended follow-up, but only $44 \%$ of infants of $<28$ weeks' GA were seen more than once. The higher rate of ROP in our study may be due to the higher proportion attending follow-up.

Other SA studies show a significant prevalence of ROP. In 1997, Gilbert et al. ${ }^{[14]}$ found that ROP accounted for $10.6 \%$ of blindness. In 1995 , Kirsten et al. ${ }^{[7]}$ showed a $31.1 \%$ prevalence of ROP in mechanically ventilated VLBW infants, with $7.1 \%$ stage 3 or worse ROP, probably owing to the exclusive inclusion of mechanically ventilated infants. In 2002, Delport et al. ${ }^{[6]}$ found a prevalence of ROP of $24.5 \%$ in VLBW infants at Kalafong Hospital, Pretoria, SA. Only two infants with a BW of $>1250$ g developed ROP, similar to our findings. The prevalence of severe ROP was 3.2\% in infants weighing $<1250 \mathrm{~g}$ at birth, with $4.3 \%$ requiring treatment, slightly higher than in our study. In a study in Johannesburg published in 2006, Mayet et al. ${ }^{[5]}$ showed a $16.3 \%$ prevalence of ROP in VLBW infants - $1.6 \%$ of infants received treatment. As in other SA studies, the majority of infants with ROP weighed $<1250 \mathrm{~g}$ and no infant weighing $>1250 \mathrm{~g}$ required treatment. The higher follow-up rate in our study may account for the apparent higher ROP prevalence. A study at Tygerberg Hospital, Cape Town, published in $2013,{ }^{[8]}$ reported an ROP prevalence of $21.8 \%$ in ELBW infants, with $4.4 \%$ of infants developing CSROP. The proportion of infants needing treatment was the same as in our study. Although the BW and GA criteria were lower than the inclusion criteria we used, the prevalences of ROP and CSROP were significantly lower, possibly because of the exclusion of infants mechanically ventilated in the first week of life.

Infants in our study with ROP had a lower mean GA and mean BW than those without, similar to other SA and certain middleincome country studies. ${ }^{[2,6,7,10,15,16]}$ On multivariate analysis, only GA was independently associated with ROP; however, GA assessment may be inaccurate as it was based on antenatal ultrasound scans, which often occurred only after 20 weeks' gestation, and/or the Ballard score, which is only accurate to \pm 2 weeks. When GA is removed from the analysis, lower $\mathrm{BW}$ remains an independent risk factor for ROP
Infants with ROP were more likely than those without to have received a blood transfusion and, as in other studies, to have late onset-sepsis. ${ }^{[16]}$ Small numbers of these patients, owing to restrictive transfusion policies and a low incidence of sepsis, prevented meaningful interpretation of their risk of developing CSROP.

In contrast to other studies citing a protective role or no effect of feeding with breastmilk, ${ }^{[17-19]}$ infants in our study who received exclusive breastmilk feeds were more likely to have ROP. Unit policy at the time restricted the use of donor breastmilk feeds to infants weighing $<1200 \mathrm{~g}$. The use of exclusive breastmilk feeding was therefore associated with lower BW, which may have been a confounder in this finding.

Previous studies have found a low occurrence of severe ROP in black infants or those with darkly pigmented fundi. ${ }^{[6,20]}$ Interpretation of this risk factor was not possible, as only black and coloured infants were represented in our cohort. Genetics may play a role in developing ROP. ${ }^{[21]}$ Only one infant in our study had a family history of ROP, which probably reflects the lack of ROP screening services in the public health sector. There were no significant differences in maternal risk factors, place of birth, mode of delivery or need for resuscitation between the groups with and without ROP.

The level of respiratory support, the need for oxygen therapy, and the occurrence of apnoea, early sepsis or severe intraventricular haemorrhage were also similar between infants with and without ROP.

The role of oxygen has been well described in the development of ROP. ${ }^{[1]}$ No statistical significance was found when comparing oxygen concentration and duration of oxygen received in the two groups. This finding may be due to strict saturation targeting in infants receiving oxygen therapy. One infant who had never received oxygen therapy developed ROP, implying that prematurity may be a more significant factor than exposure to oxygen therapy. ${ }^{[2]}$

When analysing risk factors in infants with mild/no ROP and CSROP, infants delivered via caesarean section were less likely to have CSROP. The association could be related to the potential for greater exposure to both hypoxia and hyperoxia in vaginal deliveries. Moreover, pre-eclamptic toxaemia (PET) may increase the likelihood of delivery via caesarean section. A negative correlation between ROP and PET has been described. ${ }^{[23]}$ The association of delivery via caesarean section and a decreased prevalence of ROP may be a chance one. The small numbers in our study precluded further analysis.

Successful ROP screening required extensive resources. A research assistant was employed to assist with administrative tasks, in preparation for screening and during examination. ROP examination was only available at GSH, which posed the potential problem of overcrowding with the associated risks. If patients had been transferred to step-down facilities, availability of ambulance services and accommodation in a tertiary service with limited bed capacity when transfer back for ROP examination was required would have posed challenges. Outpatient facilities, staffing and equipment had to be provided when infants were discharged before completion of screening.

Laser treatment was performed in the neonatal unit within 72 hours of diagnosis for infants requiring treatment. Challenges included the provision of theatre facilities in the neonatal unit, equipment and staffing, including the availability of a retinal surgeon. Centralised care must be considered when infants require treatment for ROP. Theatre facilities need to accommodate the specific needs of preterm infants. Facilities for treatment, in addition to skilled clinicians for ophthalmic examination and treatment of ROP, should be available before embarking on a screening programme. 
Table 2. Potential risk factors for the development of ROP $(N=135)$

\begin{tabular}{|c|c|c|c|c|c|c|}
\hline Potential risk factors & $\begin{array}{l}\text { No ROP } \\
(N=95)\end{array}$ & $\begin{array}{l}\text { ROP } \\
(N=40)\end{array}$ & $p$-value & $\begin{array}{l}\text { No or mild ROP } \\
(N=127)\end{array}$ & $\begin{array}{l}\text { CSROP } \\
(N=8)\end{array}$ & $p$-value \\
\hline \multicolumn{7}{|l|}{ Infant characteristics } \\
\hline BW $(\mathrm{g})$, mean $(\mathrm{SD})$ & $1084160)$ & 988 931) & 0.002 & $1059(172)$ & $1006(171)$ & 0.391 \\
\hline GA (wk), mean (SD) & $30.51 .9)$ & $29.21 .6)$ & $<0.001$ & $30.2(1.9)$ & $29.4(1.3)$ & 0.260 \\
\hline Racial group, $n(\%)$ & & & 0.146 & & & $0.074^{*}$ \\
\hline Black & $58(61.0)$ & $19(47.5)$ & & $75(59.1)$ & $2(25.0)$ & \\
\hline Coloured & $37(39.0)$ & $21(52.5)$ & & $52(40.9)$ & $6(75.0)$ & \\
\hline Female gender, $n(\%)$ & $50(52.6)$ & $24(60.0)$ & 0.432 & $70(55.1)$ & $4(50.0)$ & $1.000^{*}$ \\
\hline Family history of ROP, $n(\%)$ & $0(0.0)$ & $1(2.5)$ & $0.296^{*}$ & $1(0.8)$ & $0(0.0)$ & $1.000^{*}$ \\
\hline \multicolumn{7}{|l|}{ Maternal history, $n(\%)$} \\
\hline Mother VDRL-positive & $1(1.1)$ & $1(2.5)$ & $0.506^{*}$ & $2(1.6)$ & $0(0.0)$ & $1.000^{*}$ \\
\hline Mother HIV-positive & $15(15.8)$ & $7(17.5)$ & 0.806 & $21(16.5)$ & $1(12.5)$ & $1.000^{*}$ \\
\hline Maternal medication use & $39(41.1)$ & $19(47.5)$ & 0.490 & $56(44.1)$ & $2(25.0)$ & $0.466^{*}$ \\
\hline Cigarettes/tik/alcohol use & $10(10.5)$ & $6(15.0)$ & $0.377^{*}$ & $14(11.1)$ & $2(25.0)$ & $0.292^{*}$ \\
\hline Illness & $51(54.3)$ & $22(56.4)$ & 0.820 & $71(56.8)$ & $2(25.0)$ & $0.140^{*}$ \\
\hline \multicolumn{7}{|l|}{ Birth and resuscitation history } \\
\hline Outborn, $n(\%)$ & $7(7.4)$ & $3(7.5)$ & $1.000^{*}$ & $9(7.1)$ & $1(12.5)$ & $0.469^{*}$ \\
\hline Mode of delivery CS & $73(76.8)$ & $23(57.5)$ & 0.024 & $94(74.1)$ & $2(25.0)$ & $0.007^{*}$ \\
\hline \multicolumn{7}{|l|}{ Apgar score $(N=133)$, median (IQR) } \\
\hline $1 \mathrm{~min}$ & $7(4-8)$ & $7(3-8)$ & $0.796^{\dagger}$ & $7(4-8)$ & $7(3-9)$ & $0.833^{\dagger}$ \\
\hline $5 \mathrm{~min}$ & $9(7-9)$ & $9(7-9)$ & $0.775^{\dagger}$ & $9(7-9)$ & $9(6-10)$ & $0.661^{\dagger}$ \\
\hline $\begin{array}{l}\text { Resuscitation required }(N=131), \\
n(\%)\end{array}$ & $61(66.3)$ & $24(61.5)$ & 0.601 & $81(63.8)$ & $4(50.0)$ & $0.571^{*}$ \\
\hline Oxygen administered, $n(\%)$ & $74(77.9)$ & $29(72.5)$ & 0.501 & $98(77.2)$ & $5(62.5)$ & $0.394^{*}$ \\
\hline $\begin{array}{l}\text { Facemask/T-piece ventilation } \\
(N=131), n(\%)\end{array}$ & $61(66.3)$ & $24(61.5)$ & 0.601 & $81(63.8)$ & $4(50.0)$ & $0.571^{*}$ \\
\hline $\begin{array}{l}\text { Endotracheal intubation }(N=131) \text {, } \\
n(\%)\end{array}$ & $6(6.3)$ & $7(17.5)$ & 0.132 & $12(9.5)$ & $1(12.5)$ & $0.670^{*}$ \\
\hline Chest compressions $(N=131), n(\%)$ & $15(15.8)$ & $11(27.5)$ & 0.288 & $23(18.1)$ & $3(37.5)$ & $0.371^{*}$ \\
\hline \multicolumn{7}{|l|}{ Neonatal period } \\
\hline \multicolumn{7}{|l|}{ Respiratory support } \\
\hline $\mathrm{O}_{2}$ therapy, $n(\%)$ & $85(89.5)$ & $37(92.5)$ & $0.755^{*}$ & $115(90.5)$ & $7(87.5)$ & $0.565^{\star}$ \\
\hline $\begin{array}{l}\text { CPAP/HHFNC/nasal cannula } \mathrm{O}_{2} \text {, } \\
n(\%)\end{array}$ & $66(69.5)$ & $29(72.5)$ & 0.725 & $88(69.3)$ & $7(87.5)$ & $0.435^{*}$ \\
\hline Mechanical ventilation, $n(\%)$ & $19(20.0)$ & $8(20.0)$ & $1.000^{*}$ & $27(21.3)$ & $0(0.0)$ & $0.357^{*}$ \\
\hline $\begin{array}{l}\text { Duration of } \mathrm{O}_{2} \text { therapy (days), } \\
\text { median (IQR) }\end{array}$ & $4(2-8)$ & $5.5(2-14)$ & $0.360^{\dagger}$ & $5(2-10)$ & $9(4-10)$ & $0.418^{\dagger}$ \\
\hline $\begin{array}{l}\text { Highest concentration of } \mathrm{O}_{2} \\
\text { received }(N=122) \text {, median (IQR) }\end{array}$ & $0.3(0.25-0.4)$ & $0.3(0.25-0.35)$ & $0.859^{\dagger}$ & $0.3(0.25-0.38)$ & $0.3(0.3-0.35)$ & $0.582^{\dagger}$ \\
\hline Surfactant, $n(\%)$ & $27(28.4)$ & $13(32.5)$ & 0.636 & $38(29.9)$ & $2(25.0)$ & $1.000^{*}$ \\
\hline Apnoea, $n(\%)$ & $24(25.3)$ & $13(32.5)$ & 0.389 & $33(26.0)$ & $4(50.0)$ & $0.214^{*}$ \\
\hline Blood transfusion, $n(\%)$ & $12(12.6)$ & $16(40.0)$ & $<0.001$ & $26(20.5)$ & $2(25.0)$ & $0.670^{*}$ \\
\hline \multicolumn{7}{|l|}{ Sepsis, $n(\%)$} \\
\hline Early & $0(0.0)$ & $1(2.5)$ & 0.122 & $1(0.8)$ & $0(0.0)$ & $1.000^{*}$ \\
\hline Late & $2(2.1)$ & $5(12.5)$ & $0.024^{*}$ & $6(4.7)$ & $1(12.5)$ & $0.355^{*}$ \\
\hline IVH (grade 3 or 4$)(N=132), n(\%)$ & $4(4.2)$ & $0(0.0)$ & $0.553^{*}$ & $4(3.2)$ & $0(0.0)$ & $1.000^{*}$ \\
\hline Breastmilk feeds, $n(\%)$ & $28(29.5)$ & $22(55.0)$ & $0.014^{*}$ & $46(36.2)$ & $4(50.0)$ & $0.534^{*}$ \\
\hline
\end{tabular}

$\mathrm{VDRL}=$ Venereal Disease Research Laboratory; tik = methamphetamine; $\mathrm{CS}=$ caesarean section; $\mathrm{IQR}=$ interquartile range; $\mathrm{CPAP}=$ continuous positive airway pressure; $\mathrm{HHFNC}=$ humidified high-flow nasal cannula; IVH = intraventricular haemorrhage. 
The follow-up rate in this study was $91.1 \%$. Study funding ensured that resources were allocated to facilitate this. Parents were well informed, were aware of follow-up appointments and were contacted when appointments were missed. Transport costs were reimbursed if required. Despite this, 12 infants were lost to follow-up, including 2 with CSROP. The loss to follow-up rate is similar to that of Van der Merwe et al. ${ }^{[8]}$ (13.8\%), significantly lower than in other SA studies. Strengths of our study were the high enrolment and follow-up rates, which support the validity of the sample. All screening was performed by two paediatric ophthalmologists, ensuring consistency in reporting and management of ROP findings. Limitations of the study were the potential inaccuracy of GA assessment, questioning the use of this parameter in clinical guidelines for screening. Additionally, not all race groups were represented in the study population. Although the prevalence of ROP is similar to those in other SA studies, it might have been different if all race groups had been represented in the sample.

Innovative technologies may help to compensate for resource constraints for ROP screening. Retcams present a cost-effective solution with which retinal images can be obtained by trained nonopthalmologists and evaluated by remote experts with high reliability and accuracy in detecting referral-warranted ROP. ${ }^{[2]}$ Additionally, software that identifies infants at risk of developing severe ROP, such as WINROP, ${ }^{[25]}$ a web-based screening tool developed at the University of Gothenburg in Sweden, which uses an algorithm based on serial weekly neonatal body weight measurements to support ROP risk prediction. Although the use of the software is currently free, limited staffing prevented us from exploring this tool. Further studies comparing the prevalence of ROP in various provincial hospitals, possibly using retcams and WINROP, would be of value.

\section{Conclusion}

The prevalence of ROP in this study is similar to that in other reported SA studies, which do not reflect the 'third epidemic' of ROP. No infant weighing $>1250 \mathrm{~g}$ required laser treatment. The independent association of ROP with BW and the absence of ROP requiring treatment in the larger infants suggest that infants with lower BWs should be prioritised for screening in our resourcelimited setting. It was feasible to screen for ROP using the criteria in our study, but additional funded nursing and administrative assistance, skilled personnel, laser treatment, theatre facilities within or outside the neonatal unit and neonatal intensive care had to be readily accessible to infants requiring treatment. ROP screening has been implemented at GSH based on the study findings. If broader screening criteria were applied, further resources would need to be made available. However, if appropriate oxygen targets are in place, the yield of ROP requiring treatment in larger and/or more mature infants is likely to be very low.

1. Bedrossian RH, Carmichael P, Ritter J. Retinopathy of prematurity (retrolental fibroplasia) and oxygen. Clinical study. II. Further observations on the disease. Am J Ophthalmol 1954;37(1):78-86.

2. Gilbert C, Fielder A, Gordillo L, et al. Characteristics of infants with severe retinopathy of prematurity in countries with low, moderate, and high levels of development: Implications for screening programs. Pediatrics 2005;115(5):e518-e25. http://dx.doi.org/10.1542/peds.2004-1180

3. Visser L, Singh R, Young M, et al. Guideline for the prevention, screening and treatment of retinopathy of prematurity (ROP). S Afr Med J 2012;103(2):116-125. http://dx.doi.org/10.7196/samj.6305

4. Straker CA, van der Elst CW. The incidence of retinopathy of prematurity at Groote Schuur Hospital, Cape Town. S Afr Med J 1991;80(6):287-288.

5. Mayet I, Cockinos C. Retinopathy of prematurity in South Africans at a tertiary hospital: A prospective study. Eye 2006;20(1):29-31. http://dx.doi.org/10.1038/sj.eye.6701779

6. Delport SD, Swanepoel JC, Odendaal PJ, et al. Incidence of retinopathy of prematurity in very-lowbirth-weight infants born at Kalafong Hospital, Pretoria. S Afr Med J 2002;92(12):986-690.

7. Kirsten GF, van Zyl JI, le Grange M, et al. The outcome at 12 months of very-low-birth-weight infants ventilated at Tygerberg Hospital. S Afr Med J 1995;85(7):649-654.

8. Van der Merwe SK, Freeman N, Bekker A, et al. Prevalence of and risk factors for retinopathy of 8. Van der Merwe SK, Freeman N, Bekker A, et al. Prevalence of and risk factors for retinopathy of
prematurity in a cohort of preterm infants treated exclusively with non-invasive ventilation in the first prematurity in a cohort of preterm infants treated exclusively with non-invasive ventila
week after birth. S Afr Med J 2013;103(2):96-100. http://dx.doi.org/10.7196/SAMJ.6131

9. World Medical Association. World Medical Association Declaration of Helsinki. Ethical Principles 9. World Medical Association. World Medical Association Declaration of Helsinki. Ethical Principles
for Medical Research Involving Human Subjects. JAMA 2013;310(20):2191-2194. http://dx.doi. org/10.1001/jama.2013.281053

10. Perlman JM, Wyllie J, Kattwinkel J, et al. Neonatal Resuscitation: 2010 International Consensus on Cardiopulmonary Resuscitation and Emergency Cardiovascular Care Science with Treatment Recommendations. Pediatrics 2010;126(5):e1319-el344. http://dx.doi.org/10.1542/peds.2010-2972B

11. Fierson MW, Flynn J, Good W, et al. Screening examination of premature infants for retinopathy of prematurity. Pediatrics 2006;117(2):572-576. http://dx.doi.org/10.1542/peds.2005-2749

12. Good WV, Hardy RJ, Dobson V, et al. Revised indications for the treatment of retinopathy of prematurity: Results of the Early Treatment for Retinopathy of Prematurity Randomized Trial. Arch Ophthalmol 2003;121(12):1684-1696. http://dx.doi.org/10.1001/archopht.121.12.1684

13. Gole GA, Ells AL, Katz X, et al. The International Classification of Retinopathy of Prematurity revisited. Arch Ophthalmol 2005;123(7):991-999. http://dx.doi.org/10.1001/archopht.123.7.991
revere

revisited. Arch Ophthalmol 2005;123(7):991-999. http://dx.doi.org/10.1001/archopht.123.7.991
4. Gilbert C, Rahi J, Eckstein M, et al. Retinopathy of prematurity in middle-income countries. Lancet 1997;350(9070):12-14. http://dx.doi.org/10.1016/S0140-6736(97)01107-0

15. Goncalves E, Nasser LS, Martelli DR, et al. Incidence and risk factors for retinopathy of prematurity . Goncalves E, Nasser LS, Martelli DR, et al. Incidence and risk factors for retinopathy of prematurity
in a Brazilian reference service. Sao Paulo Med J 2014;132(2):85-91. http://dx.doi.org/10.1590/1516in a Brazilian referenc

16. Hakeem AH, Mohamed GB, Othman MF. Retinopathy of prematurity: A study of prevalence and risk factors. Middle East Afr J Ophthalmol 2012;19(3):289-294. http://dx.doi.org/10.4103/0974-9233.97927

17. Manzoni P, Stolfi I, Pedicino R, et al. Human milk feeding prevents retinopathy of prematurity (ROP) in preterm VLBW neonates. Early Hum Dev 2013;89(Suppl 1):S64-S68. http://dx.doi.org/10.1016/ S0378-3782(13)70019-7

18. Hylander MA, Strobino DM, Pezzullo JC, et al. Association of human milk feedings with a reduction in retinopathy of prematurity among very low birthweight infants. J Perinatol 2001;21(6):356-362. http:// dx.doi.org/10.1038/sj.jp.7210548

19. Heller $\mathrm{CD}$, O'Shea $\mathrm{M}$, Yao Q, et al. Human milk intake and retinopathy of prematurity in extremely low birth weight infants. Pediatrics 2007;120(1):1-9. http://dx.doi.org/10.1542/peds.2006-1465

20. Repka MX, Palmer EA, Tung B. Involution of retinopathy of prematurity: Cryotherapy for Retinopathy of Prematurity Cooperative Group. Arch Ophthalmol 2000;118(5):645-649. http://dx.doi.org/10.1001/
of archopht.118.5.645

21. Mohamed S, Schaa K, Cooper ME, et al. Genetic contributions to the development of retinopathy of prematurity. Pediatr Res 2009;65(2):193-197. http://dx.doi.org/10.1203/PDR.0b013e31818dldbd

22. Phelps DL. Retinopathy of prematurity: an estimate of vision loss in the United States - 1979. Pediatrics 1981;67(6):924-925

23. Yu XD, Branch DW, Karumanchi SA, et al. Preeclampsia and retinopathy of prematurity in preterm births. Pediatrics 2012;130(1):e101-107.

24. Salcone EM, Johnston S, VanderVeen S. Review of the use of digital imaging in retinopathy of prematurity screening. Semin Ophthalmol 2010;25(5-6):214-217. http://dx.doi.org/10.3109/08820538. 2010.523671

25. Lundgren P, Sjöström ES, Domellöf M, et al. WINROP identifies severe retinopathy of prematurity at an early stage in a nation-based cohort of extremely preterm infants. PLoS One 2013;8(9):e73256. http://dx.doi.org/10.1371/journal.pone.0073256

Accepted 15 August 2016. 